\title{
Hacia una geografía cultural urbana: Madrid, 1925-1936*
}

\author{
Towards an urban cultural geography: \\ Madrid, 1925-1936 \\ SUSAN LARSON \\ Professor College of Arts and Sciences. Universidad de Kentucky. USA \\ slarson@uky.edu
}

\begin{abstract}
Quisiera agradecer tanto al Prof. Javier Pérez Segura como al grupo de investigación "Arte, Arquitectura y Comunicación en la Ciudad Contemporánea" de la Universidad Complutense haberme invitado a estas $V$ Jornadas de Arte y Ciudad para comentar algunas de las ideas aparecidas en mi reciente publicación Constructing and Resisting Modernity, Madrid 1900-1936 (Construir y resistir la Modernidad, Madrid 1900-1936). Por ello, que mi intervención se desarrolle tras la lección dada por nuestro Profesor Baker no es casual, por cuanto su Materiales para escribir Madrid (1991) ha sido referencia para una generación al haber sido pionero en EEUU en los estudios urbanos y culturales, razón por la que hoy me honra y satisface compartir mesa con él.
\end{abstract}

Pretendo exponer, en primer lugar, la razón de mi investigación (el porqué de mi interés por el tema) y después reflexionar sobre mi idea de la Modernidad, concretando qué queremos decir cuando hablamos de tal en el Madrid de principios del XX, tras lo cual cerraré mi intervención afrontando cuestio-

\footnotetext{
* Transcripción revisada de la ponencia presentada en las $V$ Jornadas Internacionales Arte y Ciudad. Madrid, Universidad Complutense, 21 de noviembre de 2012.
} 
nes que entiendo básicas en la disciplina de la geografía cultural urbana, precisando cuáles son las capacidades de un acercamiento interdisciplinar y enfatizando cuánto dicha metodología contribuye a nuestro entendimiento de lo escrito en los años 30 sobre Madrid, sobre la propia ciudad.

Partiría, en mi reflexión, de una cierta insatisfacción respecto a la crítica literaria centrada en la producción cultural en el Madrid de principios del siglo pasado, al constatar la existencia de puntos obscuros (graves lagunas) en nuestra comprensión de la cultura de aquel momento y ejemplo de ello podría ser contrastar la reiteradamente tratada cultura homosexual del París, Berlín o Londres de aquellos años frente al secretismo y ocultación del tema en el Madrid del mismo momento. ¿Qué se sabía, en este sentido, en la ciudad objeto de nuestro estudio sobre las novelas que sobre el tema se leían en las citadas capitales europeas a comienzos del siglo XX? ¿Cuál fue su difusión en Madrid y en qué medida aquellos temas fueron retomados (o soslayados) por los escritores madrileños? El clamor de aquel silencio obliga a releer tanto las novelas de Eduardo Zamacois o Álvaro Retana como una larga lista de autores que buscaron aproximarse a planteamientos no heteronormativos, evidenciando la existencia de subculturas en modo alguno aisladas, idénticas en sus planteamientos a las esbozadas en Europa. Gran parte de la satisfacción que supone trabajar sobre el Madrid de comienzos del siglo XX radica, precisamente, en localizar y recuperar textos que, silenciados en su día, fueron condenados al olvido, pese a que muchos de ellos sean auténticas joyas de la literatura española. Originales en sus planteamientos y bien escritas, aquellas obras fueron ignoradas por sus contemporáneos, quienes no las valoraron por cuanto suponían de ruptura con las pautas morales (abierta en ciertos sentidos, mojigata y represora en otros) existentes en aquellos años.

Entiendo que la crítica cultural de aquellos años buscó celebrar una visión triunfalista de la clase media: por ello en mi trabajo mi intención ha sido interrelacionar el estudio de las humanidades con las ciencias sociales, razón por lo que me era fundamental detectar y diferenciar lo simbólico de lo material: y ejemplo de ello pudiera ser el cartel anunciador de la película Metrópolis de Fritz Lang (estrenada en Madrid en 1928) difundido en la prensa de la época. Tras el estreno de la película, en 1929 Buñuel publicaba una crítica en La Gaceta Literaria destacando cómo... Metrópolis colmará todas las medidas y nos asombrará como el más maravilloso libro de imágenes que se ha hecho. En su comen- 
tario, Buñuel situaba en segundo plano la labor del director, entusiasmándose por la labor del arquitecto responsable de la escenografía, entendiendo que este era el verdadero protagonista del film. De hecho, en el citado cartel anunciador, el nombre del arquitecto Otto Hunte se percibe más fácilmente que el del director Fritz Lang destacando Buñuel el hecho al comentar como la escenografía ...nos seduce con su colosal misión de la ciudad del año 2000, que podría ser anticuada o, incluso, equivocada respecto a las últimas teorizaciones de la ciudad del futuro pero que, desde el punto de vista fotogénico, es innegable su inédita propuesta, su sorprendente belleza de una profunda técnica que puede sufrir un prolongado examen sin que en un solo instante se descubra que se trata de una maqueta y no de la realidad.

Quien conozca la película sabrá bien cómo en la misma la acción se desarrolla en tres planos: existe un nivel superior que es, desde el punto de vista tecnológico, el más novedoso y en el que quienes participan en aquel mundo se sienten libres para expresarse, colaborando con Frederson, capitán de aquella industria que en el film aparece -por cuanto que trabaja literalmente dentro de un reloj, amo en consecuencia del tiempo- como dios del progreso. Un segundo nivel es el espacio destinado a unos trabajadores anónimos. Un último nivel, bajo cota, refleja con sinceridad que raya en impudor el infierno donde viven los obreros: es allí donde el hijo del capitalista actuará como intermediario entre quienes viven en segundo y tercer nivel, representados muchas veces por María, la imagen de mujer que de nuevo aparece como símbolo de modernidad. Si Frederick actúa como intermediario entre los trabajadores representados por María y su padre, en una escena su intención conciliadora se trasluce cuando toma la mano de un trabajador, simbolizando de este modo un acuerdo entre dos clases. En una película crítica en lo que respecta a la explotación de los trabajadores y donde se denuncia un capital que viola los derechos humanos, el final de la misma glosa una burguesía que apoya y auspicia la reconciliación entre los dueños de las fábricas y los trabajadores.

Metrópolis es un punto de partida sobre cómo reflexionar sobre la representación de la ciudad en los comienzos del siglo XX porque refleja y detalla las características del nivel donde a todos nos gustaría vivir. Pero las gloriosas imágenes de una ciudad del futuro ignoran por completo los niveles más grises de aquella ciudad se reflejan igualmente en el edificio Carrión, proyectado por Martínez Feduchi y Eced, y las zonas tan dispares como Cuatro 
Caminos, Carabanchel, Vallecas..., donde se edificaba otra cara de la Modernidad, distinta de los espacios de negocios y ocio localizados en Gran Vía. Al contraponer en mi trabajo unas y otras, dejaba claro cómo la intención no era tanto "exhibir" las novedosas imágenes de una clase capaz de trastocar la antigua trama urbana cuanto valorar en qué medida la narrativa (cine o novela) reflejan la realidad cotidiana de quienes vivían fuera de la modernidad, fuera de una singularidad ajena -en su cotidianidad- a la vida de la mayoría de los españoles.

Contrastar espacios domésticos, sus usos y su diseño, entender cuánto más allá del gesto un mismo problema es susceptible de ser encarado de diferentes formas, es el tema de mi atención. Recientemente se ha comentado cuál era el uso de los espacios domésticos reflexionando no tanto sobre el diseño de la cocina, baño, dormitorios o estar cuanto buscando comprender cómo se entendían aquellos espacios. Cierto que es difícil localizar en el cine mudo imágenes que describan el uso de aquellos espacios: sin embargo en la literatura (por ejemplo, en la novela de Carmen de Burgos titulada La rampa) se encuentra una detallada descripción no sólo de aquellos espacios sino de cuanto un trabajador acaba pagando mensualmente por carbón, por el arreglo de su ropa, por alimentos tales como café, verduras o leche... convirtiéndose entonces esta literatura (la literatura popular y no la canónica) en extraordinaria fuente de información sobre la vida cotidiana de los madrileños de la época.

He hecho referencia al cine mudo porque, tras haber trabajado durante tiempo sobre el mismo en la España de comienzos de siglo, entiendo como sólo una docena larga de largometrajes (localizados en la Filmoteca Nacional) ofrecen imágenes de aquel Madrid: por esta razón es preciso (dado además que conocemos mal la producción cinematográfica española anterior a 1936) centrar el estudio en la prensa popular por cuanto será en esta donde aparezca mayor información no ya sobre la Modernidad oficial que consagra la madrileña Gran Vía sino sobre la realidad y la vida cotidiana sobre la vida diaria, sobre lo que los madrileños de la época entendieron era su habitual forma de vida.

¿Qué fue entonces la Modernidad? Para muchos, Ortega y Gasset es pauta y fuente de autoridad en el debate sobre qué fue la modernidad en aquella 
España. En uno de los números de su Revista de Occidente Ortega -quien a menudo usaba metáforas arquitectónicas y urbanas al hablar de Modernidadseñalaba cómo ...en la sazón presente adquiere mayor urgencia ese afán de conocer por donde va el mundo, pues surgen, por donde quieran, los síntomas de una profunda transformación en las ideas, los sentimientos, las maneras, en las instituciones. Muchas gentes comienzan a sentir la penosa impresión de ver su existencia invadida por el caos y, sin embargo, un poco de claridad, un poco de orden en la formación les revelaría pronto el plano de la nueva arquitectura en que la vida occidental se está construyendo. Desde una visión jerárquica, buscando establecer un orden en un mundo cada vez más moderno y, en consecuencia, caótico, su visión coincidía con la de quienes en los comienzos de aquel siglo planteaban una estructura urbana alejada del antihigienismo, criminalidad y tugurificación que caracterizaba a los centros históricos. En una visión triunfalista, el sueño de la modernidad se oponía no sólo a la realidad sino también a quienes desde supuestos científicos buscaban la reconfiguración del espacio urbano.

En la literatura, filosofía y pensamiento de aquellos años la figura de José Díaz Hernández llama poderosamente la atención y quisiera comentar el libro por él escrito en 1930 (El nuevo romanticismo) demasiado a menudo ignorado pese a que se redactara como alternativa a la Deshumanización del arte, de Ortega y Gasset, publicado en 1925. Si en la obra de Ortega se recurría frecuentemente a la metáfora (reclamada por una joven vanguardia como herencia gongorina) Díaz Hernández, sólo cinco años después de haber publicado Ortega su libro, se referirá a la metáfora como lenguaje que debiera estar en manos de todos, enfatizando que la metáfora era bien conocida y frecuentemente utilizada en el lenguaje común de los españoles, planteando en consecuencia -frente a la visión elitista de Ortega- la necesidad de entender ...el arte para la vida y la vida para el arte. En este sentido no sería casual que Díaz Hernández diera a su editorial (buscando situarse en las antípodas de Ortega) el nombre de "Editorial Oriental", diferenciándose así de la orteguiana Revista de Occidente. De este modo, Díaz Hernández participaría del elenco de filósofos, críticos y artistas que buscan explorar otra forma de representar la ciudad y cuyo estudio reclamo.

Que no quedan sorpresas: lo que planteo en modo alguno es novedoso sino que entronca con la reflexión esbozada por geógrafos e historiadores, por quienes desde planteamientos interdisciplinares valoran la modernidad como 
proceso de comprensión del tiempo y del espacio, como proceso simultáneo de construcción y destrucción. David Harvey publicó en 2003 Paris, Capital of Modernity y en aquel trabajo buscó comprender de qué manera el capital no sólo fluyó y creó el centro cultural más importante del siglo XIX. En este sentido, si analizamos tanto el espacio urbano como la estructura del barrio o la propia manzana podemos ver cuánto el capitalismo depende de la circulación del dinero; en este sentido la cita a Harvey o a Metropolis cabría complementarse con una idea expuesta por un Balzac que señalaba como L'espoir est une mémoire que désire.

La esperanza se convierte así en referencia: si para Harvey (quien en su texto ha destacado cómo ...precisamos un espacio de la esperanza, espacio que se nutre tanto de recuerdos como de deseo por trastocar el presente) la reflexión se plantea sobre un presente inconcluso, para Balzac ...no cabe considerar el presente, ni como punto de llegada del pasado, ni como premonición de futuro. Uno y otro reflejan como el deseo de reescribir o de reconstruir un espacio de esperanza va en contra de un Poder que celebra y consume el presente como si fuera objeto de cambio, capaz de conducirnos en consecuencia a un futuro inmediato sin problemas. Y ese concepto de espacio de esperanza es el que nos ha permitido comprender el impulso de los artistas por representar la ciudad, por crear visiones utópicas (y también distópicas) de la ciudad entendida como crítica social.

La relación recíproca entre el artista y los hombres (no ha habido, hasta el momento, tantas mujeres que tuvieran el poder necesario para replantear la ciudad) aparece en el citado proyecto de Martínez Feduchi, de un arquitecto no sólo tracista del edificio Capitol sino también reputado autor de escenografías en numerosas películas españolas. Cierto que fue responsable de definir aquellos espacios en películas como Raza: pero no olvidemos que años antes, y en una casi desconocida película titulada El bailarín y el trabajador ofrecía una ambientación que reflejaba la modernidad del Decó, demostrando cuánto fue capaz en su reflexión de simultanear lo que antes definía como plan superior en la Metrópolis de Lang (¿qué, sino eso, era la solución de esquina dada al edificio Capitol, imponiendo su presencia en un punto en el que la calle quebraba la línea recta y resolvía a modo de charnela la fuerte pendiente que desde ahí conducía hasta Plaza de España?) al tiempo que 
jugaba con su imagen a la calle (con su volumen más que con su fachada) entendiendo este como ejemplo de la modernidad madrileña.

Quienes han trabajado sobre los estudios culturales y se han preocupado por la geografía cultural, a menudo han citado el concepto definido por Henry Lefebvre de "espacio social" y, en consecuencia, han reflexionado sobre la producción de dicho espacio social. Para el pensador francés ...el espacio social es producto de las acciones del pasado, lo que permite crear tanto acciones nuevas como impedir otras. En ambos casos, algunas se reflejan en el proceso de la producción, otras en el consumo. Resulta pues que el espacio social se basa en la diversidad de saberes. En consecuencia, la diversidad de saberes que se encuentran en los varios discursos de modernidad evidencia en cuanto unos fueron reconocidos ( $\mathrm{y}$, en consecuencia, triunfaron) mientras que otros, silenciados serían ignorados. Si para Lefebvre la complejidad de lo concebido, lo percibido y lo vivido marcaba un modo de compresión, tal idea ha sido retomada -entre ellos- por Franco Moretti, profesor de literatura comparada de la Universidad de Columbia, quien en su texto Graphs, Maps, Trees: Abstract Models for Literary History apunta -al refrerirse a los mapas literarios- cómo ...la función de los mapas literarios es, en buena manera facilitar el análisis de los textos al reducir estos a elementos básicos que permiten hacer abstracción de lo que cabría definir como flujo narrativo espacial. Es decir, hacer ver de qué manera los protagonistas del relato literario ocupan el espacio urbano apropiándose del mismo y haciendo ver cómo está internamente ligado a su comportamiento. Para ello se exige construir un artefacto subjetivo, un mapa de sensaciones tan artificial como el texto mismo y, con un poco de suerte, de nuevo estos mapas serán más que la suma de las partes, conteniendo cualidades emergentes no visibles en una primera lectura.

La idea de construir mapas literarios para buscar comprender dónde se desarrollan ciertos sucesos en las novelas más sociales, cabe también aplicarlo a otras novelas de vanguardia o lo que la cuestión se centra en reflexionar sobre cuánto ello nos permite conocer mejor la ciudad. No olvidemos un hecho singular: los mapas mienten no tanto porque ven una falsa información sino porque nosotros tendemos a extrapolar datos ignorando lo general. En este sentido, tiene previsto el plano de Madrid que elaboraron en 1940 los Servicios Técnicos de la FET de Valladolid presidirá en cuanto la realidad de la ciudad que se refleja (levantamiento tan fidedigno como su época fuera el 
plano de Texeira) oculta la realidad de una ciudad destruida por los tres años de bombardeos que padeciera durante su asedio.

Entre los mapas geográficos, los mapas de sensaciones y experiencias: es entonces en este sentido donde centro el último punto de mi presentación y para ello quisiera referirme a la novela La Venus mecánica del mismo José Díaz Fernández antes mencionado. Publicada en 1929, la novela contrapone a dos protagonistas: una mujer (Obdulia) quien poco antes había abandonado el mundo rural para buscar en la metrópolis su futuro o, lo que es lo mismo, su independencia económica y un hombre (Víctor), intelectual y periodista. Casi toda la acción se sitúa bien en la Gran Vía bien es sus inmediaciones y la trama gira sobre el papel del intelectual burgués en la sociedad española de la década de los 20, reiterando el dilema al cuestionarse sobre cuál debiera ser su papel en la sociedad, dudando sobre una opción individualista o asumiendo, por el contrario, una propuesta colectivista. En un momento en el que la social española vive fuertes cambios políticos, los sentimientos de Obdulia son bien distintos y configuran casi el asunto de la novela, centrando su atención en cómo la mujer busca su libertad en el ambiente urbano. Por ello en determinado momento apunta cómo ....algún día ha de llegar en que no existan esas muchachas perdidas, indecisas, que merodean alrededor del bar económico donde han comido alguna vez; no se atreven a entrar porque en el fondo de su bolso no hay más que la pólvora exprimida, la barra de carmín redonda y chiquita como un dedo recién mutilado y la factura sin pagar de la última fonda. Muchachas de zapatos gastados y sombreros deslucidos que buscan un empleo y terminan por encontrar un amante. Un pintor actual podría retratar en ellas la desolación de una urbe; al fondo la valla de un solar, a la izquierda, un desmonte y, más lejos, la espalda iluminada de un rascacielos.

El componente urbano es claramente distópico, como se refleja cuando Víctor se desprecia a sí mismo al saberse (al reconocerse) como personaje que disfruta de las mujeres de la calle, valorándolas solo como objetos de consumo y comentando sobre las que pasean por la Gran Vía cuanto (más que mujeres) ...son esquemas de mujeres, como en las pinturas de Picasso, pura geometría - donde ha quedado la línea sucinta e imprescindible. La realidad en que figuran no era ya un producto natural, sino artificial. Era una sutil colaboración de la máquina y la industria de la técnica y el arte; alimentos concentrados, brisas artificiales del automóvil y del ventilador electrónico; yodos artificiales del tocador, sombras de 
cinema y claridades de gas. Esa mujer es hija de los ingenieros, de los modistas, de los perfumistas, de los operadores, de los mecánicos. Desde esta lógica, el título de la novela La Venus mecánica refleja la deshumanización de la mujer que llega con la esperanza de encontrar en la urbe su independencia. Más que la crítica literaria me ha interesado el acercamiento cartográfico-literario, buscan defender cuanto los distintos narradores que aparecen en la obra ofrecen cada uno una experiencia muy diferente y una valoración de la ciudad muy distinta. Cabría, en un tema desarrollar de manera más monográfica, confrontar la experiencia masculina de la ciudad y la femenina de unos mismos espacios. De manera diferente se valoran y entienden espacios de ocio tales como el Teatro Alcázar, el Eslava, donde Obdulia y Víctor se conocen, en la Puerta del Sol, por supuesto, el Ritz, en el hall del Palace, del mismo modo que convendría reflexionar la razón por la que los hombres que figuran en la novela nunca cambian de residencia mientras que las mujeres se mudarán de manera constante, ocupando barrios tan diferentes como la calle Luchana -en Chamberí-, Pardiñas (en el barrio de Salamanca) o Guzmán el Bueno, en Argüelles.

El estudio de las emociones no sólo se percibe en la distinta valoración del ocio sino también en los hechos políticos que marcan aquellos días: así, por ejemplo, en la novela se describe una muy violenta manifestación que tiene lugar en la Gran Vía tantas veces mencionada; tal acontecimiento ofrece una nueva visión de un espacio que en este momento se valoraba desde pautas distintas. Si Víctor contempla cuanto acontece desde la habitación de un hotel de lujo localizada en una en las últimas plantas de uno de los edificios de altura situados en el eje, casi simultáneamente Obdulia se encuentra en la calle donde será golpeada por la policía percibiendo, en consecuencia, la violencia de manera muy distinta. Ocurre sin embargo que ni la percepción de Víctor ni la de Obdulia son completas por lo que, al ser parciales y subjetivas, son solo interpretaciones de una realidad. A esto cabría añadir, además, cuanto la existencia de un espacio masculino y otro femenino en modo alguno significa que no existan intersecciones entre ambos, espacios de coincidencia que se percibe no sólo la manifestación sino también en el ocio, cuando Víctor acude como cliente a espacios lúdicos y donde Obdulia -quien trabaja en los mismos como tanguista, bailando con quien paga por ello- percibe el mismo espacio desde valoraciones bien distintas. 
Si hombres y mujeres valoran de distinta forma un mismo espacio, en un Madrid politizado los militantes de los partidos de derechas e izquierdas viven, al mismo tiempo, experiencias diferentes del mismo modo que aquellos que pertenecen a la clase media utilizan la ciudad de forma distinta a quienes configuran la clase obrera. El objeto entonces de mi investigación es analizar cómo aquellos modelos sociales de comienzos del siglo XX representaron los espacios madrileños, permitiéndonos comprender cómo los discursos de la modernidad no son exclusivamente los discursos oficialistas y hubo, simultáneamente, un lado obscuro (pero no por ello menos importante) del que hoy todavía sabemos poco.

\section{Bibliografia}

BAKER, Edward (1991): Materiales para construir Madrid. Literatura y espacio urbano de Moratín a Galdós. Siglo XXI, Madrid.

BuRGOS, Carmen de (1927): La rampa. Renacimiento, Madrid.

DÍAZ FERNÁNDEZ, José (1929): La Venus mecánica. Renacimiento, Madrid.

_(1930): El nuevo romanticismo. Polémica de arte, política y literatura. Zeus, Madrid.

GUBERN, Roman, et al. (2009): Historia del cine español. Cátedra, Madrid.

HARVEY, David ( 2003): Paris, Capital of Modernity. Routledge, Nueva York.

LARSON, Susan (2011): Constructing and Resisting Modernity. Madrid 1900-1936.

Vervuert Iberoamericana, Madrid.

Lefebvre, Henri (1991): The Production of Space. Trad. Donald NicholsonSmith. Blackwell, Londres. [1974]

MORETTI, Franco (2005): Graphs, Maps, Trees: Abstract Models for a Literary History. Verso, Nueva York.

ORTEGA Y GASSET, José (1925): La deshumanización del arte e ideas sobre la novela. Revista de Occidente, Madrid. 